Second Language Research 24,3 (2008); pp. 267-295

\title{
Factors of success and failure in the acquisition of grammatical gender in Dutch
}

\author{
Leonie Cornips Meertens Institute, Royal Netherlands \\ Academy of Sciences and \\ Aafke Hulk University of Amsterdam
}

Received February 2007; revised December 2007; accepted December 2007

\begin{abstract}
The goal of this article is to examine the factors that are proposed in the literature to explain the success-failure in the child L2 (second language) acquisition of grammatical gender in Dutch definite determiners. Focusing on four different groups of bilingual children, we discuss four external success factors put forward in the literature: (1) early age of onset, (2) lengthy and intensive input, (3) the quality of the input and (4) the role of the other language. We argue that the first two factors may indeed contribute to explaining the differences in success between the less and more successful bilingual children. However, the influence of the quality of the input in (standard) Dutch appears to be inconclusive, whereas the (structural) similarity of the gender systems in the two languages may reinforce the children's awareness of the grammatical gender category. Moreover, it appears that individual bilingualism vs. societal bilingualism, that is the sociolinguistic context in which Dutch is acquired, is not a factor for failure or success with respect to the acquisition of grammatical gender. In the final part of this article, we hypothesize that the important role of the input is related to a language internal factor, which distinguishes the Dutch gender system of the definite determiner from that of other languages, resulting in different acquisition paths.
\end{abstract}

Keywords: grammatical gender, child bilingualism, Dutch, quality and quantity of input, sociolinguistic context

Address for correspondence: Leonie Cornips, Meertens Institute, Royal Netherlands Academy of Sciences, Joan Muyskenweg 25, PO Box 94264, 1090 GG Amsterdam, The Netherlands; email: leonie.cornips@meertens.knaw.nl 


\section{Introduction}

Recent work by Schwartz (2003), Haznedar (2003), Unsworth (2005) and others explicitly examines various morphosyntactic phenomena in child second language (L2) acquisition and raises important questions concerning issues such as age of first exposure and the influence of the children's other language (for an overview of the literature on child L2 acquisition, see Paradis, 2007).

In this article, we are interested in the acquisition of grammatical gender in Dutch, which is, as yet, a relatively unexplored area in child language (but see Müller, 2000; Gathercole et al., 2001; Möhring, 2001; Kupisch et al., 2002). According to Franceschina (2005), the child L2 acquisition of grammatical gender shows a development that is very similar to what happens in first language (L1) acquisition, even in cases where one of the two languages does not have gender. Recent studies on the acquisition of grammatical gender in Dutch with learners belonging to different groups of child L2 learners (see below) have, however, shown that the development of grammatical gender in the Dutch of bilingual children does sometimes differ from what is reported for monolingual children.

The aim of this article is to examine and compare the following factors of success and failure mentioned in the literature discussing (experimental) data on the bilingual acquisition of definite determiners in Dutch:

- the age of onset;

- the length of exposure;

- the quality of the input; and

- the role of the other language.

We will label the different child acquirers presented in the literature all as bilingual, even though their age of first exposure to Dutch varies and some could in fact be described as bilingual first language (2L1) acquirers and others as child L2 learners. Some of these children grew up bilingually from birth; others migrated to the Netherlands with their parents between birth and age four, or even later. These bilingual children also differ with respect to their sociolinguistic (learning) contexts; these determine the quantity and quality of the standard Dutch input to which 
these children are exposed. There are children who grew up in a bilingual community of the 'old' type and of the 'new' type. The 'old' type refers to bidialectal communities in non-standard language areas in the Netherlands where children acquire a local dialect in addition to the standard language and are therefore raised bilingually from birth or from school age onwards. The 'new' type is the result of population shifts, namely immigrants who entered the Netherlands and who have started to use the Dutch language without completely taking over the grammatical system that exists in the grammar of native Dutch speakers. As such, the (grand)parents of these bilingual children acquired Dutch as adult L2 speakers in a non-instructed context. Finally, there are the children raised in expatriate families; these children have grown up bilingually in an otherwise monolingual (Dutch) community, often in a one-parent-one-language family context.

We show that the external success factors discussed in the literature all involve the role of the input, and we hypothesize that these factors are crucially related to a grammatical, language-internal factor that distinguishes the Dutch gender system of the definite determiner from that of the children's other languages, where the acquisition path is also different.

Grammatical gender in Dutch is reflected in a number of agreeing elements accompanying the noun or referring to it. ${ }^{1}$ Common nouns take the singular definite determiner $d e$, and neuter nouns take the singular definite determiner het. The gender distinction is not marked on the plural definite determiner, which is always de, nor on the singular indefinite determiner, which is always een. According to a dictionary-based estimate (token-analysis), roughly $75 \%$ of Dutch nouns are common and only $25 \%$ are neuter. Van Berkum (1996) found that in running texts the relative distribution of $d e$ - and het-words is roughly 2:1. As a result, de appears by far most frequently in the input to Dutch children.

Spontaneous as well as experimental production data regarding the acquisition of the gender of definite determiners in monolingual Dutch child language reveal that until the age of six, monolingual children have serious problems with neuter gender (compare Bol and Kuiken,

\footnotetext{
${ }^{1}$ For a more extensive description of the Dutch system, see the introduction to this issue.
} 
1988; Van Kampen and Wijnen, 2000: 275; Van der Velde, 2003; 2004; Blom et al., this issue): they massively overgeneralize $d e$ with (singular) neuter nouns but they infrequently (incorrectly) produce het with common nouns. The overgeneralization in one direction and the late age at which the monolingual children are targetlike makes Dutch different from other languages - such as German, French and Spanish - where the L1 acquisition of grammatical gender is not a late phenomenon and it does not show similar unidirectional overgeneralization properties (Franceschina, 2005). German is particularly relevant in this respect since it also has neuter gender determiners, and these have not been reported to present specific problems in acquisition (Mills, 1986).

The question we are interested in is whether bilingual children show the same pattern of development in the acquisition of grammatical gender in Dutch as monolingual children. To be more specific, we seek to determine whether and for what reasons the neuter gender definite determiner het has been found to be more problematic for bilingual children as it is for monolingual children. Table 1 presents a schematic overview of the different types of bilingual children, revealing their increasing rate of success in the acquisition of gender of the Dutch definite determiner, as reported in the literature (see this literature for an extensive discussion about children involved, data collection, methodology, etc.). ${ }^{2}$

This article is organized as follows. In the following sections, we discuss one by one the (external) factors of success-failure proposed in the literature to (partly) explain the particularities of the bilingual acquisition path in Dutch in each of the different groups of bilingual children. In the last section, we suggest that these factors can be related to a linguistic factor, internal to the morphosyntax of Dutch, that plays a crucial role in the acquisition of grammatical gender of definite determiners in Dutch. ${ }^{3}$

\footnotetext{
${ }^{2}$ Importantly, these studies differ in many respects regarding methodology, number of participants, age of testing, other language, etc. Therefore, we have to be extremely cautious in comparing and interpreting the results: the best we can hope for is to find tendencies.

${ }^{3}$ We leave aside all other aspects of both the acquisition of determiners and of grammatical gender, and refer the reader to the relevant literature for these issues. Further research will have to show whether our suggestions for the acquisition of grammatical gender in the definite determiner can be extended to the acquisition of grammatical gender in adjectives and relatives (compare Cornips et al., 2006).
} 
Leonie Cornips and Aafke Hulk 271

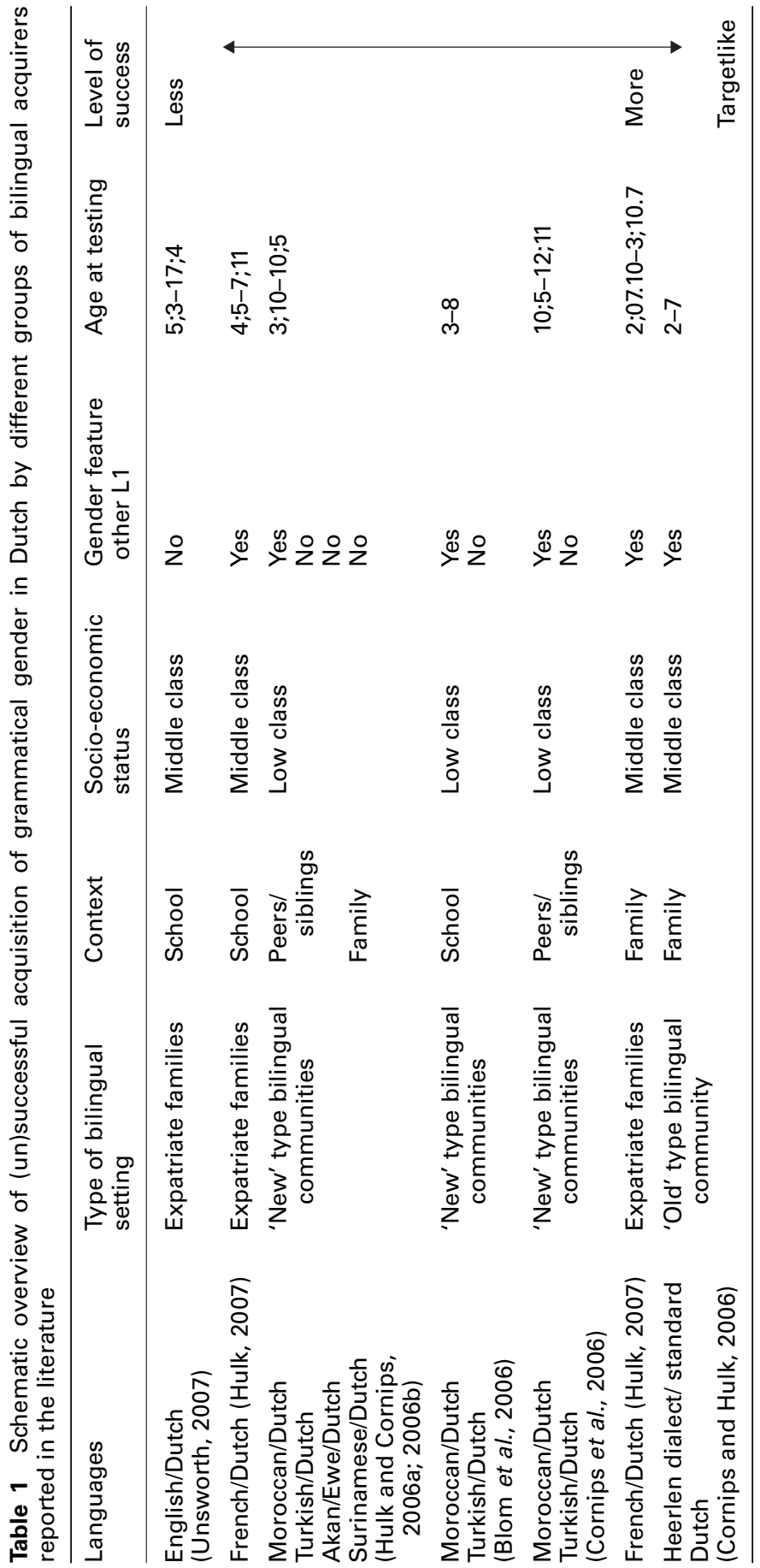




\section{Factors for success-failure: age of onset: a new critical age?}

At least since the seminal work by Lenneberg (1967), differences between L1 acquisition and (adult) L2 acquisition have been related to the age of onset of acquisition, although this continues to be a much debated issue. The main idea is that there is a sensitive period for grammatical development. Whereas Lenneberg thought that the critical age was around puberty, since then it has generally been assumed that the end of such an optimal period lies around age seven or eight (for a recent overview, see Hyltenstam and Abrahamsson, 2003). The implicit assumption that before age seven the age of onset has no influence on either the development or the ultimate attainment of the child's acquisition has recently been questioned. This issue can be related to the distinction which is made between child L2 acquisition, on the one hand, and 2L1 acquisition, on the other. The age of onset for child L2 acquisition is generally assumed to be between age four and seven (Schwartz, 2003; Unsworth, 2005), whereas for 2L1 acquisition the age of onset is ideally the moment of birth (see De Houwer, 1990). The period between birth and age four is as yet an unexplored area, although Meisel (2007) considers this period to belong to $2 \mathrm{~L} 1$ acquisition. He suggests that at around age three to four, changes in the acquisition patterns are brought about by neurological maturation, resulting in modification of the human 'language making capacity'. In other words, according to Meisel, age three to four would constitute another critical age for language acquisition.

Let us now consider what role this factor has been claimed to play in the success-failure of each of the four groups of bilingual children, i.e. children whose first exposure to Dutch (1) widely varies, but is after age four and (2) children whose first exposure is at birth, and children growing up in bilingual families and surrounding bilingual communities of the (3) 'new' and (4) 'old' type. In what follows, we first very briefly summarize in each subsection in what respect the bilingual children studied are found to be successful or not in the acquisition of grammatical gender on the determiner category (D).

\section{Bilingual children from expatriate families with Dutch input after age four}

Two studies (Hulk, 2007; Unsworth, 2007) examine bilingual children growing up in expatriate families in which most of the children 
were exposed to Dutch between age four and seven at school. These children would generally be characterized as child L2 learners of Dutch. Importantly, in an elicited production task the bilingual children in both studies showed a similar development to monolingual children in that they initially produced $d e$ with both neuter and common nouns (for more detailed information about the data collection method and the number of participants involved in these studies, see Table 2). The vast majority of the bilingual children, however, differed from monolingual children in that they had not (yet) attained targetlike levels of the neuter definite determiner, that is, the mean error-rate was about $75 \%$ (503/674) in Unsworth's and 70\% (76/109) in Hulk's study. Interestingly, there were a few English-Dutch children who overgeneralized het. Furthermore, individual analyses revealed that there was one English-Dutch child and three French-Dutch children who were targetlike.

The results of Unsworth's study could, in principle, reveal a difference in success-failure related to the age of onset. However, the five children whose age of first exposure was seven and who were nontargetlike in their production, all had only a short and limited/moderate exposure to Dutch when they were tested. Therefore, according to Unsworth, no firm conclusions about the role of the age of onset can be made on the basis of these children. Similarly, no clear conclusions can be made on the basis of Hulk's (2007) data from the French-Dutch children either. There is no exact information about their age of onset and, moreover, this probably also interacts with length of exposure.

Table 2 Bilingual English-Dutch and French-Dutch results for the neuter definite determiner by an elicited production task

\begin{tabular}{|c|c|c|c|c|c|c|}
\hline & \multicolumn{3}{|c|}{ Unsworth, 2007a } & \multicolumn{3}{|c|}{ Hulk, 2007b } \\
\hline $\begin{array}{l}\text { Language } \\
\text { Age } \\
n \\
\text { Exposure to Dutch }\end{array}$ & \multicolumn{3}{|c|}{$\begin{array}{l}\text { English-Dutch } \\
5 ; 3-17 ; 4 \\
58 \\
0-7 ; 3\end{array}$} & \multicolumn{3}{|c|}{$\begin{array}{l}\text { French-Dutcl } \\
4 ; 5-7 ; 11 \\
17 \\
\text { around } 4^{c}\end{array}$} \\
\hline $\begin{array}{l}\text { Determiner } \\
\text { produced with } \\
\text { neuter nouns }\end{array}$ & $\begin{array}{l}\text { de } \\
\text { het }\end{array}$ & $\begin{array}{l}503 / 674 \\
171 / 674\end{array}$ & $\begin{array}{l}74.6 \% \\
25.4 \%\end{array}$ & $\begin{array}{l}\text { de } \\
\text { het }\end{array}$ & $\begin{array}{l}76 / 109 \\
33 / 109\end{array}$ & $\begin{array}{l}69.7 \% \\
30.3 \%\end{array}$ \\
\hline
\end{tabular}

Notes: a Data-collection: semi-spontaneous data using a picture description task; ${ }^{\mathrm{b}}$ Data-collection: picture description task telling a story; ${ }^{\mathrm{c}}$ Unfortunately, no more precise information about the age of onset is available to us. 


\section{Factors of success and failure}

\section{Bilingual children growing up in bilingual communities of the 'new' type}

All the studies on bilingual children in bilingual communities of the 'new' type (see Blom et al., 2006; this issue; Cornips et al., 2006; Hulk and Cornips, 2006a; 2006b; for details, see Table 3) show that from age three onwards, both the bilingual children and the monolingual controls clearly overgeneralized $d e$ and used it with neuter nouns. However, there is an important difference between the monolingual and bilingual children, namely that in contrast to their monolingual peers, the oldest bilinguals (between ages 9;3 and 10;5) did not reach a targetlike use of het. This raises the question of whether the difference between bilinguals and monolinguals is qualitative or quantitative or, to put it differently, whether the bilingual children have a different representation of neuter gender in their Dutch grammar compared to monolingual children, or whether they are simply much slower in their development, showing a considerable delay. If we consider the advanced age of the children in the Cornips et al. (2006) study, i.e. 10;5-12;11, these results seem to support the hypothesis of a qualitative difference, and they may be indicative of fossilization in a non-target stage. However, what is important to note is that these older children also overgeneralized het to common nouns

Table 3 Bilingual ethnic minority and monolingual results for the neuter definite determiner by picture description tasks

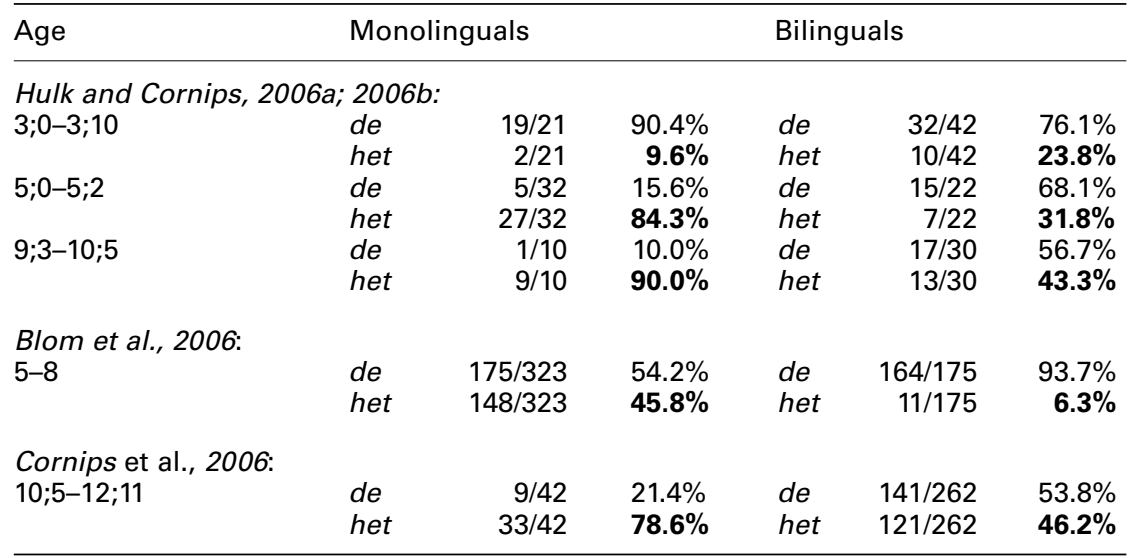

Notes: Binlinguals in Hulk and Cornips studies are Ghanaian (Akan/Ewe), Turkish, Suriname and Moroccan families; bilinguals in Blom et al. and in Cornips et al. studies are Turkish and Moroccan children 
(24\%, 68/288), albeit to a lesser extent than the use of de with neuter nouns $(54 \%, 141 / 262)$. Monolinguals, in contrast, only revealed a $4 \%$ (2/48) overgeneralization of het to common nouns (Cornips et al., 2006).

The $24 \%$ overgeneralization of het by the bilinguals seems to suggest that they have some active knowledge of het. It raises the intriguing question as to whether the initial and persistent overgeneralization of de could be, at this older age at least, the effect of a speech production problem, rather than a lack of knowledge regarding the gender of the definite determiner. ${ }^{4}$ Brouwer et al. (2008) try to shed light on this question by using an experiment designed to 'tap the knowledge' of monolingual $(n=18)$ and bilingual children $(n=24)$ between 11 - and 13-years-old. Interestingly, the results show that the bilingual children did not really misrepresent the gender specification of $d e$ as compatible with both common and neuter nouns. Nevertheless, it is certainly not the case that the bilingual children possessed the right knowledge (yet) about gender specification in Dutch either: the accuracy rates were too low (about 40\%) and significantly lower than the accuracy rates of the monolingual controls (about 90\%). All we can say is that these bilingual children showed (some) awareness of the gender specification of the definite determiner in Dutch. Later (see Section VI.1), we explain these results in terms of a language internal factor, which distinguishes the Dutch gender system of the definite determiner from that of other languages, resulting in different acquisition paths. The question now is whether this can be related to their age of onset in some way.

In this respect, it is interesting to point out that the results regarding the production data of Blom et al. (2006) and Hulk and Cornips $(2006 \mathrm{a} ; 2006 \mathrm{~b})$ do not differ, whereas the former analysed the bilingual children exposed to Dutch only after age four, and the latter analysed them as being exposed to Dutch before age four. This could mean that age four is not a critical age, contrary to what has been suggested by Meisel (2007), at least not for the acquisition of grammatical gender in Dutch. However, it is very hard to establish the exact age of onset for the acquisition of Dutch in these communities: Blom et al. adopt age four as the age of onset, and therefore they considered these

\footnotetext{
${ }^{4}$ Such a mapping problem could be similar to Lardiere's (2005) findings concerning the L2 acquisition of English verbal morphology by a fossilized Chinese speaker.
} 
children as child L2 learners. ${ }^{5}$ In Hulk and Cornips (2006a; 2006b) a slightly different perspective is chosen. There, we provided substantial evidence for the claim that, nowadays, in Moroccan and Turkish families Dutch is always spoken at home (see Jongenburger and Aarssen, 2001). For these families, the heritage language is used more with mothers than with fathers, and Dutch is used more between siblings (for a more elaborate discussion of the languages used by these children in different contexts, see Cornips and Hulk, 2006a). Taken together, these results suggest that 'age of onset' does not appear to be a decisive factor here.

\section{Children growing up bilingually from birth in expatriate families, in a 'one parent - one language' context}

Hulk (2007) considers longitudinal, spontaneous production data from two French-Dutch girls, Anouk and Annick, who were raised bilingually from birth (from the Amsterdam-corpus of Hulk and Van der Linden). All the grammatical gender errors of Anouk and Annick between ages 3;1.4 and 3;10.7 consisted of the use of (the common) de with a neuter noun instead of het. Anouk was considerably slower in her development than Annick and the monolingual children. We unfortunately do not have sufficient data with a definite determiner from her on which to base any firm conclusions. At an age of 3;4.10, Annick overgeneralized at a rate of $29 \%(2 / 7)$. This is comparable to the error percentage that has been found by Van der Velde for monolingual Dutch children (Van der Velde, 2003; 2004). What is more, Annick already produced het around age three: she did not appear to be delayed, contrary to what has been found for bilingual children in a 'one parent one language' setting with an age of onset between age four and seven. Moreover, Annick's results were similar to what has been reported by De Houwer. De Houwer (1990: 123, 125) extensively discusses the early stages of development for the Dutch-English bilingual child,

\footnotetext{
${ }^{5}$ In Blom et al. (2007) the decision to define a bilingual child as an L2 child is based on the teacher's responses on a shortened version of the 'Questionnaire on the child's multilingual context'. In Hulk and Cornips (2006a; 2006b) and Cornips et al. (2006) the children themselves were asked to inform us about their exposure to Dutch, e.g. their language choices with (grand)parents, siblings and friends.
} 
Kate. Between 2;7 and 3;7, her spontaneous speech data showed an overgeneralization of de with $50 \%$ of neuter nouns.

\section{Bilingual children growing up in bilingual communities of the 'old' type}

Interestingly, bidialectal children acquiring standard Dutch and a local dialect are completely different from the bilingual ones growing up in bilingual communities of the 'new' type and in 'one parent - one language' families in that they appear to be more advanced than the monolingual controls from age four onwards. They used the neuter definite determiner het at a higher percentage by age five and, from this age onwards, they were already above chance level. Numbers were low; we therefore have to be cautious in interpreting these results, but the tendency was clearly different from the one found regarding the other bilingual children (for details, see Cornips and Hulk, 2006).

The bidialectal children in question were raised in a sociolinguistic context that is both different from and similar to the bilingual children growing up in bilingual communities of the 'new' type. It is different because the parents of the bidialectal children are not adult L2 speakers of Dutch but are balanced bilinguals themselves, speaking both the local dialect and standard Dutch as native speakers (see Cornips, 1998). It is similar, however, in that the bidialectal children have also been raised bilingually, both in the family and community domains. There is no 'one parent - one language' setting per se but language choice patterns depend on, for example, particular interlocutors. Irrespective of any differences between these bidialectal children in this domain, the claim that they were exposed to standard Dutch before they went to school is uncontroversial.

\section{Summary}

Notwithstanding possible interaction with other factors, there are quantitative differences in the correct use of het between the different groups of bilingual child learners that might relate to their age of onset. Across the board, the bilingual children who are not born in the Netherlands seem to do worse, but their home language is generally not Dutch. The bilingual children from the 'new' bilingual communities do not perform 
much better. We argued that their exact age of onset is hard to establish but that there is generally some contact with (non-native) Dutch from birth onwards. Finally, the bidialectal children (of 'old' bilingual communities) and the children raised bilingually from birth do best. Given the possible interaction with other factors of success and failure, this hierarchy cannot be used to support the role of the age of onset as a decisive success factor, but it certainly does not constitute counterevidence for such a role either. At the very least, it supports the idea that the role of input is an important factor. Another aspect of the input is considered in the next section.

\section{Factors for success-failure: quantity of the input: threshold effects?}

Sorace (2005) has argued that interface domains present an inherent problem for acquisition since the acquisition of constructions/phenomena requiring the integration of syntactic knowledge and knowledge from other domains is more complex than those involving syntactic knowledge only. Interestingly, she also discusses the role of the input in relation to such integration problems. She suggests that quantitative and qualitative differences between the input of monolinguals and bilinguals may have 'destabilizing' effects and may affect emerging grammars in different ways. Her hypothesis is that quantitative differences in the input are likely to affect processing abilities because of fewer opportunities to integrate syntax and other knowledge in interpretation and production, whereas qualitative differences may affect representations because of insufficient evidence for interface mappings. Importantly, the acquisition of the gender feature as expressed in the definite determiner involves the interface between the lexicon and morphosyntax. Therefore, following Sorace (2005), we expect that quantitative and qualitative differences between monolingual and bilingual grammars are possible when the input is below a certain threshold. We first look at the quantity of the input and, in the next section, we consider the quality of the input.

There is a quantitative difference between the Dutch input the bilingual children receive in each of their two languages and the input the monolingual children receive. However, the studies considered here show that this more limited input does not necessarily lead to a delay, 
since both the $2 \mathrm{~L} 1$ child Annick and the bidialectal children are very similar in their development to monolingual children. What about the other bilingual children?

\section{Bilingual children from expatriate families with Dutch input after age four}

Unsworth (2007) explicitly addresses the role of length of exposure in her work on English-Dutch bilingual children. She found that three of her participants produced het with more than $70 \%$ of neuter nouns but there was only one completely targetlike child. These participants had a lengthy and (relatively) intense exposure to Dutch, which suggests the importance of input for the acquisition of this particular phenomenon. Unsworth argues that her data suggest that lengthy exposure to Dutch is necessary for targetlike acquisition of grammatical gender in Dutch but it is not sufficient, i.e. extensive exposure is also required (see also Unsworth, this issue).

\section{Bilingual children growing up in bilingual communities of the 'new' type}

A comparison between the different age groups of bilingual children from 'new' bilingual communities ranging from age 3;0 to $10 ; 5$ clearly reveals a (slow) development in the production of correct het and a decrease of incorrect de with neuter nouns (see Hulk and Cornips, 2006). Unlike the monolingual peers, there was still some development in the age range between 5;0 and 9;3, although the bilinguals did not reach the same level of ultimate attainment. The development at an advanced age may support the hypothesis that length of exposure/ quantity of input plays a role in the acquisition of grammatical gender of the definite determiner.

\section{Frequency}

Another way of investigating the quantity of the input is to look for a correlation between the frequency of (neuter) words and their acquisition. The token frequency of the definite determiner het, as opposed to that of $d e$ is very low in Dutch discourse in general, and thus even more infrequent in the input to bilingual children. Brouwer et al. (2008) took 
this aspect into account and found that the bilingual children from these 'new' communities consistently accepted and rejected congruent and incongruent determiner-noun pairs, respectively, when the nouns were very frequent. However, when the nouns in question were infrequent, they showed an inconsistent pattern. This suggests a frequency effect, supporting the hypothesis that the acquisition of grammatical gender in Dutch is sensitive to the quantity of input in this respect, too (see also Unsworth this issue for similar findings).

\section{Summary}

All bilingual children are exposed to less input in both their languages than their monolingual peers. This in itself is not necessarily a factor for failure with respect to the acquisition of grammatical gender in Dutch, as shown by the targetlike development of some of the bilingual children. Nevertheless, the results of the bilingual children whose home language is not standard Dutch and the frequency effect found by Brouwer et al. suggest that the quantity of the input does play a role. This raises the question of how to establish the threshold in the input to be reached for bilingual children to be successful in this domain.

\section{Factors for success-failure: the quality of the input: the sociolinguistic context}

\section{Bilingual children from expatriate families}

It is safe to assume that the quality of the input the children are exposed to from the expatriate families in Unsworth's study comes mainly from Dutch peers and teachers at school and, as a result, is targetlike (see Unsworth this issue for motivation). As for Anouk and Annick, who are growing up bilingually from birth in a 'one parent - one language' context, it is also plausible to assume that the quality of the input in Dutch from their L1 Dutch parent is excellent.

\section{Bilingual children growing up in bilingual communities of the 'new' type}

We mentioned earlier that Dutch is increasingly used at home in communities of the new type. However, the (grand)parents of these children did 
not acquire Dutch as L1 speakers but as adult L2 speakers in a noninstructed context. Moreover, immigrants and their descendants live in communities that consist of closed networks due to chain migration: the family or community may function quite autonomously within mainstream society and there is no routine of daily conversations with native speakers of Dutch. This has important consequences for the quality of the input to which these immigrant children are exposed. However, children of Turkish and Moroccan descent differ from children from Surinamese descent in this respect. The command of Dutch by the first-generation Surinamese immigrants is standard-like due to the long period of contact with Dutch since colonial times. Furthermore, Surinamese households in which Sranan is spoken are generally oriented towards Dutch and none of the Surinamese participants claim to speak Sranan better than Dutch (Jongenburger and Aarssen, 2001). It is also reported elsewhere (Appel and Schoonen, 2005) that children in Surinamese families often acquire Dutch as their first language. These differences may account for the fact that the youngest 3-year-old Surinamese children in Hulk and Cornips' study (2006b) performed much better and revealed an increasingly correct use of het between three and five years old, in contrast to the Moroccan and Ghanaian children of the same age.

Interestingly, sociolinguistic research has shown not only that adult L2 speakers of Dutch widely overgeneralize de with all nouns (Muysken, 1984), but also that the use of $d e$ in some adolescent groups of these ethnic communities functions as a kind of group 'identifier' (see Cornips, 2008).

\section{Bidialectal children}

Contrary to the bilingual children in communities of the 'new' type, the (grand)parents of the bidialectal children are all bidialectal themselves and their Dutch does not differ from standard Dutch with respect to grammatical gender. Thus, the quality of the standard Dutch input to which these children are exposed is excellent.

\section{Summary}

Summarizing, the quality of the input appears to be a significant factor in communities of the 'new' type only. Its influence is supported by the 
observed difference in success rates with respect to the correct use of het; for details of a more sociolinguistic explanation of the (quality of the) input in some of the ethnic minority communities, see Cornips and Hulk (2006).

\section{Factors for success-failure: the other language: conditions for cross-linguistic influence}

The discussions in the literature on adult L2 acquisition of grammatical gender all address the role of the L1. Globally speaking there are two main perspectives:

- learners can acquire grammatical gender in their L2 regardless of whether this feature is present in their L1 (Bruhn de Gavarito and White, 2000; White et al., 2001);

- the functional feature make-up of the L1 prevents (a subset of) L2 learners from becoming fully targetlike (Hawkins and Franceschina, 2004; Franceschina, 2005).

Interestingly, Sabourin (2001) argues that just having gender in the L1 may not be sufficient, and that the (gender system in the) two languages should also be closely related in a way to be specified. Her data on the L2 acquisition of Dutch by three different groups of L1 speakers German, French and English - shows that the German group performed best and that the French group did better than the English, suggesting that the morphosyntactic overlap between the Dutch and German gender systems has had a positive, cross-linguistic influence. Let us now consider whether the L1 plays a role in the development of the bilingual children considered here.

\section{Bilingual children from expatriate families}

The bilingual children from the expatriate families in Unsworth's and Hulk's studies have as other language English and French, languages without and with a gender distinction in its determiner system, respectively. However, both English-Dutch and French-Dutch bilingual children performed equally poorly on the acquisition of the neuter definite determiner in Dutch. This suggests that the L1/other language is not 
a decisive factor for success or failure. It might be the case that the French gender system - which is different from Dutch in that it distinguishes masculine from feminine and not neuter from common - is not similar enough to Dutch in order to have a positive cross-linguistic influence, as suggested by Sabourin for adult L2 acquisition.

\section{Bilingual children from bilingual communities of the 'new' type}

The bilingual child data showed that there were no differences in success rates between children from Moroccan and Turkish communities, although Moroccan-Arabic and Berber have some form of gender and Turkish does not (Cornips et al., 2006). The MoroccanArabic and Berber gender system, however, is structurally very different from or unrelated to the Dutch gender system (see Cornips and Hulk, 2006).

\section{Bilingual children from bilingual communities of the 'old' type}

There were considerable differences in success rates between the children from the bidialectal community and all the other bilingual children we studied. Interestingly, the gender system in the Heerlen dialect is very closely related to that of standard Dutch, much more so than the French or the Moroccan-Arabic/Berber system. ${ }^{6}$ As in standard Dutch, it makes a distinction between neuter and common and, in contrast to standard Dutch, it also distinguishes masculine and feminine within the class of common nouns (see Table 4). Moreover, it makes all these distinctions in the indefinite determiner system, too, which enhances the saliency of grammatical gender-marking.

Table 4 Definite and indefinite determiners in the local dialect of Heerlen

\begin{tabular}{llll}
\hline & Masculine & Feminine & Neuter \\
\hline Indefinite & inne & ing & e \\
Definite & d'r & de & 't \\
\hline
\end{tabular}

\footnotetext{
${ }^{6}$ The close relation between standard Dutch and the Heerlen dialect holds for both the lexicon and morphosyntax.
} 
It might be the case that, thanks to the input from the Heerlen dialect, the bidialectal children have a greater awareness of gender distinctions in general and of neuter gender-marking in particular, and this may help them in their acquisition of gender in standard Dutch. These children had, however, also had a lengthy and intensive exposure to standard Dutch, in contrast to the other groups of bilingual children. Therefore, we have to be cautious in interpreting the decisiveness of the role of the other language here.

\section{Summary: yes, there is cross-linguistic influence, but ...}

Cross-linguistic influence is a well-known factor for success in bilingual language acquisition (see, among others, Hulk and Müller, 2000; Müller and Hulk, 2001). Nevertheless, the data from the literature studied here show that for the other language to contribute to the success of the acquisition of grammatical gender on D in bilingual Dutch, the conditions seem to be very narrowly defined: only the bidialectal children with another language which morphosyntactically overlaps with standard Dutch appeared to experience some positive cross-linguistic influence. Clearly, further research about the exact amount of overlap necessary for success in this domain is needed.

\section{Summary: the role of the input}

Among all the different bilingual child learners, the bidialectal ones were found to be the most successful. They were exposed to a qualitatively excellent standard Dutch from birth onwards, and they had also had a lengthy and intensive exposure to standard Dutch. Furthermore, their other language has a gender system, which is closely related to and overlaps with that of standard Dutch. Without any doubt, all these (external) factors together have contributed to their successful acquisition of grammatical gender of the definite determiner in Dutch. It is, unfortunately, not yet possible to establish which of these factors is the crucial one.

Nevertheless, all factors discussed relate to the role of the input. This raises the question as to why the acquisition of the Dutch gender system of the definite determiner is so sensitive to input. To put it 
differently, can we find an internal, linguistic factor that may explain this sensitivity?

\section{What makes Dutch so special? An internal, linguistic factor}

An issue we have not yet addressed is the difference between the acquisition of grammatical gender in Dutch and the acquisition of grammatical gender in other languages. Indeed, problems of the type found in both Dutch L1, 2L1 and adult/child L2 acquisition are not mentioned anywhere in the literature for the (bilingual) acquisition of gender in other languages (for a recent overview, see Franceschina, 2005). The acquisition of grammatical gender in Dutch appears to be special in two respects:

- until a very advanced age only de is produced as definite determiner, regardless of the gender of the noun;

- this overgeneralization goes in one direction only. ${ }^{7}$

One might argue that the patterns observed in the acquisition of the definite determiner result from the frequency of $d e$ in the Dutch input, because there are many more $d e$-words than het-words. Although this may play an important role in explaining the delay in the development of (most) bilingual children from the literature studied, it cannot be the whole story. On the one hand, it is especially unclear why most of the older bilingual children seem to fossilize in a non-target stage regarding the acquisition of Dutch grammatical gender, when this is not a general characteristic of their performance in other phenomena of Dutch morphosyntax (see Hulk and Cornips, 2005). On the other hand, there are clear differences in the rate of (ultimate) success of the different groups of bilingual children. If frequency were the crucial factor, we would not expect the different groups of bilinguals to differ in the extent of the delay they experience compared to their monolingual peers. Therefore, we would like to offer some speculative suggestions related to the acquisition of grammatical features in more theoretical terms in the next section.

\footnotetext{
${ }^{7}$ Here we only consider grammatical gender in Dutch definite determiners; but see Blom et al. (this issue) for grammatical gender in adjectives and Cornips et al. (2006) in adjectives and relative pronouns.
} 


\section{Some speculations about a possible internal factor}

We follow Hawkins and Franceschina (2004) who assume that D has an uninterpretable grammatical gender feature that has to be erased/checked by the lexical gender feature of the noun. ${ }^{8}$ They hypothesize that children initially do not have this grammatical gender feature on D in their grammar. Their (non-targetlike) use of different forms of the determiner is not based on grammatical concord with the noun, but on other strategies, such as phonological cues. A point in development comes, according to Hawkins and Franceschina, when the grammatical feature on $\mathrm{D}$ is triggered; thereafter, the use of determiners is targetlike. These authors mention as possible triggers the paradigmatic link between definite and indefinite articles and input above a certain threshold. Let us consider Dutch with respect to these suggestions.

Recall that the saliency of grammatical gender on D in the Dutch input is very low: grammatical gender is not evident in the morphology of the indefinite determiner (which is een for both neuter and common nouns), nor on the plural of the definite determiner (which is de for all nouns). The only clear evidence for gender on $\mathrm{D}$ can be found in the opposition between de and het in the singular definite determiner, and between die and dat in the singular demonstrative determiner. ${ }^{9}$ However, even in these domains, given the frequency differences between neuter and common nouns, the saliency of the relevant contrast is not very high. ${ }^{10}$ In fact, the most salient evidence for features of D in the Dutch input is the opposition definite - indefinite. Therefore, we follow Hawkins and Franceschina (2004) in assuming that initially, young children both monolingual and bilingual have no gender-specification in their Dutch grammar. Now, in order to explain their default production of $d e$ both with common and neuter nouns in this period, we hypothesize that this is related to the early presence of another grammatical feature

\footnotetext{
${ }^{8}$ The proposal by Hawkins and Franceschina (2004) is explicitly made for L2 acquisition of Romance languages. However, they suggest that this acquisition path must also hold for L1 acquisition.

${ }^{9}$ Although there is some evidence for grammatical gender on adnominal adjectives in Dutch, this is different from the marking on determiners and not very salient (see the introduction to this issue); this issue is left aside here.

${ }^{10}$ The one notable exception with respect to saliency are diminutives, which are all morphologically marked by a suffix on the noun and which all take het, regardless of the lexical gender of the noun (see Section VI.2).
} 
in their grammar. Let us suppose here for the sake of the argument that this is def. ${ }^{11}$ At a certain moment (see also Hawkins et al.), the children become aware of gender playing a role and they add a grammatical gender feature to their grammar. Let us assume that initially this feature is underspecified. This is a (very) unstable stage in which considerable variation in the choice/spell out of the definite determiner is to be expected, where the initial default choice de is plausibly (still) the most frequent. In other words, we would expect the production of both $d e$ and het with the same noun at this stage. This also implies the (incorrect) production of het with common nouns, contrary to the overgeneralization in one direction which was observed in the earlier stages of development.

Interestingly, in the literature on the production of bilingual children from communities of the 'new' type, both cases are mentioned:

- production of de and het with the same neuter noun: Hulk and Cornips' (2006a) experimental results showing that several bilingual children produce both de and het for the same neuter noun; ${ }^{12}$

- (incorrect) production of het with a common noun: Cornips et al. (2006) show that bilingual children from the 'new' communities around age 11 incorrectly produced het with common nouns at a rate of 24\% (68/288), producing strings such as het appel (the- $<$ neuter $>$ apple $<$ common $>$ ). Their monolingual peer controls (age-matched) were also found to make this error but only in $4 \%(2 / 48)$ of cases. This is a significant difference. Interestingly, Unsworth (2007) mentions that six of her bilingual (child L2) children produce more than $20 \%$ of common words with het. ${ }^{13}$

Let us go back to the hypothesized development in the acquisition of the gender feature specification and speculate on the question of how

\footnotetext{
${ }^{11}$ For some suggestions about the grammatical feature count being involved in the (acquisition of the) Dutch definite determiner, see Roodenburg and Hulk, 2007.

${ }^{12}$ In that article, we suggested that it could be the case that these children have acquired the correct specific neuter value of the gender feature, but that they somehow have problems with its correct morphological spell-out as het on the definite determiner, using the default form de instead. Such an explanation is compatible with the slightly different line we suggest here.

${ }^{13}$ It is not entirely clear in her work at what stage of acquisition these bilingual children are in.
} 
children progress beyond this unstable stage. Although we did not discuss it in any detail and there are not many data on the overgeneralization of het to common nouns for monolingual Dutch children, we assume that the monolingual children have left this stage around age six or seven, when they are reported to behave in a targetlike fashion (Bol and Kuiken, 1988; Van Kampen and Wijnen, 2000: 275; Van der Velde, 2003; 2004; but see Blom et al., this issue). It is plausible to assume following the suggestion of Hawkins and Franceschina (2004) and discussions in the literature - that this happens after a certain threshold in the input has been reached.

Interestingly, it could also be the case that the specification of the value of the gender feature on $\mathrm{D}$ in Dutch and its independent status as a grammatical feature is due to a specific characteristic of the input, as mentioned in the literature on Dutch monolingual children, namely: the awareness of the neuter gender selection for diminutives (see also Van der Velde 2003; 2004). Note that in Dutch, regardless of its (lexical) gender, any singular noun taking the diminutive suffix $-(t) j e$ 'becomes' neuter and takes het as singular, definite determiner:

- het boek (neuter def.det book) $\rightarrow$ het boekje (neuter def.det book-DIM)

- de tafel (non-neuter def.det table) $\rightarrow$ het tafeltje (neuter def.det table-DIM)

Recent experimental results (a picture description task; see Van Ginkel, 2006; Cornips and Hulk, 2007) provide further evidence that diminutives trigger the specification of the value of the gender feature since monolingual children in two age groups - i.e. 6;0-7;6 $(n=8)$ and $10 ; 3-11 ; 5(n=8)$ - performed better in the correct use of het with diminutives $(81 \%(103 / 128)$ and $91 \%(117 / 128)$, respectively) than with other neuter nouns (49\% (47/96) and 79\% (76/96), respectively). ${ }^{14}$ Van Ginkel suggests that the children only do this after they have become aware of the head-status of the diminutive suffix. However, in the case of bilingual Turkish-Dutch children of the same age groups in this same experiment, Van Ginkel found that the diminutive did not seem to trigger the selection of the definite determiner het, not even at

\footnotetext{
14 The term 'trigger' (taken from Hawkins and Franceschina, 2004) is used in the sense of 'bootstrap'.
} 
an age of between 10;0 and 11;10. At that age, the Turkish-Dutch children overgeneralized de with $41 \%$ (53/130) of singular, neuter nouns and with $34 \%$ (58/172) of diminutives. ${ }^{15}$ This raises interesting questions as to the reason for this difference between monolingual and bilingual children in this respect, such as the possible relation with the age at which these bilingual children become aware of the morphological complexity of the diminutive words. If this is not yet the case at age 10, it is not surprising that these children are still in an unstable stage where they are aware of grammatical gender but have not yet acquired neuter as the specific value of an independent grammatical feature/functional projection in the nominal domain. Clearly, further research is necessary here for all the different groups of bilingual children in order to be able to relate the morphosyntactic theoretical characteristics of the input to the acquisition path of grammatical gender in the Dutch definite determiner and beyond.

\section{Concluding remarks}

The goal of this article was to examine the (external) factors that have been proposed in the literature to explain the success-failure in the child L2 acquisition of grammatical gender in Dutch definite determiners. We have made a distinction between four different groups of bilingual participants discussed in the relevant literature. First of all, it is important to note that being bilingual in itself is not a factor for failure (or success) with respect to the acquisition of grammatical gender in Dutch, nor is a specific sociolinguistic context such as community/societal bilingualism. External success factors put forward in the literature are (1) early age of onset and (2) lengthy and intensive input. We have seen that these two factors may indeed explain the differences in success between the less successful bilingual children from expatriate families and 'new' bilingual communities, on the one hand, and the children growing up bidialectally from birth, on the other. In contrast, it is harder to show the influence of (3) the quality of the input in (standard) Dutch. This factor contrasts the children from the new bilingual

\footnotetext{
${ }^{15}$ There are no results available yet on the acquisition of gender with diminutives by the other groups of bilingual learners, but for similar results for bilingual children from expatriate families, see Unsworth (this issue).
} 
communities with all other children since their (grand)parents as immigrants, and their descendants, have acquired an adult L2 Dutch that is often not nativelike and, furthermore, this 'ethnic' Dutch is characterized by the overgeneralization of de (Cornips and Hulk, 2006). Experimental data from these bilingual children between 11 and 13 years old seem to show some fossilization in an unstable stage where both het and de are used for both neuter and common words. However, it is as yet unclear whether this is correlated to the quality of the input, since some sociolinguistic research suggests that particularly the persistent use of $d e$ for neuter words has some kind of in-group identification role (Cornips, 2008). The (4) role of the other language as a factor for success-failure in the acquisition of gender is much debated in the literature on adult L2 acquisition. In this article, we discussed the literature showing that bidialectal children performed better than the bilingual children who had French or Moroccan-Arabic/Berber as the other language, even though these languages have gender distinctions in their determiner system. Moreover, we saw that there were no clear indications that the children who had English or Turkish as the other language performed worse. One of the factors of success might be that the other L1 must have a gender system that overlaps with that of standard Dutch, as is the case with the Heerlen dialect. Thus, the similarity of the gender systems in the two languages may reinforce the awareness of grammatical gender and consequently influences the success rate of acquisition of grammatical gender.

We showed that these success factors all involved the input in one way or another. Obviously, it is not simply a matter of differences in frequencies between de and het with het being much less frequent in adult Dutch (input) than $d e$. If it were, we would not expect clear differences in the rate of (ultimate) success for the different groups of bilingual children or, maybe it is safer to say, we would not expect the different groups of bilinguals to differ in the extent of the delay they experience compared to their monolingual peers. The bilingual children show numerous individual differences in this respect, much more than the monolinguals.

In the last part of this article, we tentatively suggested that the role of the input might be related to a language internal factor, which distinguishes the Dutch gender system of the definite determiner from that of 
other languages and which results in different acquisition paths, namely that Dutch has the characteristic property that grammatical gender on D is dependent on definiteness, contrary to what we see in Romance languages or other Germanic languages. Grammatical gender in Dutch is less transparent and prominent for the language learner, who may need considerable input to become aware of grammatical gender playing a role in the morphosyntactic make-up of determiners in Dutch. We tentatively assumed (following Hawkins and Franceschina, 2004) that initially both monolingual and bilingual children do not have grammatical gender in their Dutch grammar; rather, their grammars contain a definiteness feature only, and this results in the default production of de with all definite nouns. Moreover, we hypothesized that the acquisition of grammatical gender takes place in two steps. First, it is added as an underspecified feature, giving rise to a variable use of de/het with all nouns. Second, it becomes fully specified resulting in the correct use of de/het. Further research should consider the extent to which the quality and quantity of the input plays a role in the acquisition of the full specification of this grammatical feature.

In suggesting a (crucial) relation between the role of the input and the type of underspecified feature in the acquisition process, we predict that there should be other (interface) features of this type (and in other languages) for which a similar, slow path of development is to be expected, with an unstable situation and maybe even fossilization as a possible outcome. We hope to also explore these ideas in future work.

\section{References}

Appel, R. and Schoonen, R. 2005: Street language: a multilingual youth register in the Netherlands. Journal of Multilingual and Multicultural Development 26, 85-117.

Blom, E., Polišenská, D. and Weerman, F. 2006: Effects of age in the acquisition of gender: a three-way distinction between child L1, child L2 and adult L2 acquisition. Unpublished talk presented at the Amsterdam Gender Colloquium, Vrije Universiteit, Amsterdam, September.

2007: Effects of age on the acquisition of agreement inflection. Morphology $16,313-36$.

— this issue: Articles, adjectives and age of onset: the acquisition of Dutch grammatical gender. Second Language Research 24. 
Bol, G.W. and Kuiken, F. 1988: Grammaticale analyse van taalontwikkelingsstoornissen [Grammatical analysis of language development deficits]. Unpublished doctoral dissertation, University of Amsterdam.

Brouwer, S., Cornips, L. and Hulk, A. 2008: Misrepresentation of Dutch neuter gender older bilingual children? In Haznedar, B. and Gavruseva, E., editors, Current trends in child second language acquisition: a generative perspective. Amsterdam: John Benjamins, 83-96.

Bruhn de Garavito, J. and White, L. 2000: Second language acquisition of Spanish DPs: the status of grammatical features. In Skarabela, B., Fish, S.A. and Do, H.-J.A., editors, Proceedings of the 24th Boston University Conference on Language Development. Somerville, MA: Cascadilla, $164-75$.

Cornips, L. 1998: Syntactic variation, parameters and their social distribution. Language Variation and Change 10, 1-21.

2008: Losing grammatical gender in Dutch. The result of bilingual acquisition and/or an act of identity? Journal of Bilingualism 12.

Cornips, L. and Hulk, A. 2006: External and internal factors in bilingual and bidialectal language development: grammatical gender of the Dutch definite determiner. In Lefebvre, C., White, L. and Jourdan, C., editors, L2 acquisition and creole genesis: dialogues. Amsterdam: John Benjamins, 355-78.

- 2007: Diminutives and gender awareness in bilingual acquisition. Unpublished talk presented at the 6th International Symposium on Bilingualism, University of Hamburg, June.

Cornips, L., van der Hoek, M. and Verwer, R. 2006: The acquisition of grammatical gender in bilingual child acquisition of Dutch (by older Moroccan and Turkish children). In Los, B. and van de Weijer, J., editors, Linguistics in the Netherlands 2006, 40-51.

De Houwer, A. 1990: The acquisition of two languages from birth: a case study. Cambridge: Cambridge University Press.

Franceschina, F. 2005: Fossilized second language grammars: the acquisition of grammatical gender. Amsterdam: John Benjamins.

Gathercole, V.C.M., Thomas, E.M. and Laporte, N.I. 2001: The acquisition of grammatical gender in Welsh. Journal of Celtic Language Learning Special Issue: First Language Acquisition 6, 53-87.

Hawkins, R. and Franceschina, F. 2004: Explaining the acquisition and nonacquisition of determiner-noun gender concord in French and Spanish. In Prevost, P. and Paradis, J., editors, The acquisition of French in different contexts: focus on functional categories. Amsterdam: John Benjamins, 175-205.

Haznedar, B. 2003: The status of functional categories in child L2 acquisition: evidence from the acquisition of CP. Second Language Research 19, 1-41.

Hulk, A. 2007: Deviance in early child bilingualism. In Camacho, J., FloresFerrán, N., Sánchez, L., Déprez, V. and Cabrera, M.J., editors, Romance 
Linguistics 2006: Selected papers from the 36th Linguistic Symposium on Romance Languages. Amsterdam/Philadelphia: John Benjamins, 177-98.

Hulk, A. and Cornips, L. 2005: Differences and similarities between L2 and (2)L1: DO- support in child Dutch. In Dekydtspotter, L., Sprouse, R.A. and Liljestrand, A., editors, Proceedings of the 7th Generative Approaches to Second language Acquisition Conference. Somerville, MA: Cacadilla Press, 163-77.

2006a: Neuter gender and interface vulnerability in child L2/2L1 Dutch. In Unsworth, S., Parodi, T., Sorace, A. and Young-Scholten, M., editors, Paths of development in L1 and L2 acquisition. Amsterdam: John Benjamins, 107-34.

2006b: Between 2L1 and child L2 acquisition: an experimental study of bilingual Dutch. In Lleo, C., editor, Interfaces in multilingualism: acquisition and representation. Amsterdam: John Benjamins, 115-37.

Hulk, A. and Müller, N. 2000: Bilingual first language acquisition at the interface between syntax and pragmatics. Bilingualism: Language and Cognition 3, 227-44.

Hyltenstam, K. and Abrahamsson, N. 2003: Maturational constraints in SLA. In Doughty, C.J. and Long, M.H., editors, Handbook of second language acquisition. Oxford: Blackwell, 539-88.

Jongenburger, W. and Aarssen, J. 2001: Linguistic and cultural exchange and appropriation: a survey study in a multi-ethnic neighbourhood in the Netherlands. Journal of Multilingual and Multicultural Development 22, 293-308.

Kupisch, T., Müller, N. and Cantone, K. 2002: Gender in monolingual and bilingual first language acquisition: comparing Italian and French. Lingue e Linguaggio 1, 107-49.

Lardiere, D. 2005: On morphological competence. In Dekydtspotter, L., Sprouse, R.A. and Liljestrand, A., editors, Proceedings of the 7th Generative Approaches to Second Language Acquisition Conference. Somerville, MA: Cascadilla Press, 178-92.

Lenneberg, J. 1967: Biological foundations of language. New York: John Wiley.

Meisel, J. 2007: Child second language acquisition or successive first language acquisition? Hamburg Working Papers in Multilingualism 80, 33-64.

Mills, A.E. 1986: The acquisition of gender: evidence from German and English. Berlin: Springer.

Möhring, A. 2001: The acquisition of French by German children of preschool age: an empirical investigation of gender assignment and gender agreement. In Foster-Cohen, S.H. and Nizegorodcew, A., editors, EUROSLA Yearbook 2001. Amsterdam, John Benjamins, 171-93.

Müller, N. 2000: Gender and number in acquisition. In Unterbeck, B., Rissanen, M., Nevalainen, N. and Saari, M., editors, Gender in grammar and cognition. Berlin: Mouton de Gruyter, 351-400. 
Müller, N. and Hulk, A. 2001: Cross-linguistic influence in bilingual first language acquisition: Italian and French as recipient languages. Bilingualism: Language and Cognition 4, 1-21.

Muysken, P. 1984: Attitudes and experiences of discrimination: the Netherlandic of Moroccan foreign workers. In Deprez, K., editor, Sociolinguistics in the Low Countries. Amsterdam: John Benjamins, 333-56.

Paradis, J. 2007: Second language acquisition in childhood. In Hoff, E. and Shatz, M., editors, Handbook of language development. Oxford: Blackwell, 387-405.

Roodenburg, J. and Hulk, A. 2007: Puzzles on grammatical gender. Unpublished talk presented at the XXXIII Incontro di grammatica generativa, Bologna, Italy.

Sabourin, L. 2001: L1 effects on the processing of grammatical gender in L2. In Foster-Cohen, S.H. and Nizegorodcew, A., editors, EUROSLA Yearbook 2001, 159-69.

Schwartz, B.D. 2003: Child L2 acquisition: paving the way. In Beachley, B., Brown, A. and Colin, F., editors, Proceedings of the 27th Boston University Conference on Language Development, Somerville, MA: Cascadila Press, 26-50.

Sorace, A. 2005: Selective optionality in language development. In Cornips, L. and Corrigan, K.P., editors, Syntax and variation: reconciling the biological with the social, Amsterdam: John Benjamins, 55-80.

Unsworth, S. 2005: Child L1, adult L2, child L1: differences and similarities: a study on the acquisition of direct object scrambling in Dutch. Doctoral dissertation, Utrecht University. Dissertation series 119. Utrecht: LOT. 2007: Age and input in early child bilingualism: the acquisition of grammatical gender in Dutch. In Belikova, A., Meroni, L. and Umeda, M., editors, Galana 2: Proceedings of the Conference on Generative Approaches to Language Acquisition North America 2. Somerville, MA: Cascadilla Press, 448-58.

- this issue: Age and input in the acquisition of grammatical gender in Dutch. Second Language Research 24.

Van Berkum, J.J.A. 1996: The psycholinguistics of grammatical gender: studies in language comprehension and production. Doctoral dissertation, Max Planck Institute. Nijmegen: Nijmegen University Press.

Van Ginkel, B. 2006: De verwerving van lexicaal en morfologisch bepaald geslacht [The acquisition of lexical and morphological gender]. Unpublished Masters thesis, Meertens Institute, University of Utrecht.

Van Kampen, J. and Wijnen, F. 2000: Grammaticale ontwikkeling [Grammatical development]. In Gillis, S. and Schaerlaekens, A.M., editors, Kindertaalverwerving: een handboek voor het Nederlands [Child language acquisition: a handbook for Dutch]. Groningen: Martinus Nijhoff, 225-285. 
Van der Velde, M. 2003: Déterminants et pronoms en néerlandais et en français: syntaxe et acquisition [Determiners and pronouns in Dutch and French: syntax and acquisition]. Unpublished doctoral dissertation, University of Paris 8, France. Available online at http://umr7023.free.fr/ Downloads/MvdVeldeTh_somm.html (March 2008).

2004: L'acquisition des déterminants en L1: une étude comparative entre le français et le néerlandais [The acquisition of L1 determiners: a comparative study of French and Dutch]. Acquisition et Interaction en Langue Etrangère 21, 9-46.

White, L., Valenzuela, E., Kozlowska-Macgregor, M., Leung, I. and Ayed Koslow, H.B. 2001: The status of abstract features in interlanguage: Gender and number in L2 Spanish. In Do, A. H-J., Dominguez, L. and Johansen, A., Proceedings of the 25th Boston University Conference on Language Development, Somerville, MA: Cascadilla Press, 792-802. 